\title{
FGF-23 and PTH levels in patients with acute kidney injury: A cross-sectional case series study
}

MaryAnn Zhang ${ }^{1}$, Raymond Hsu², Chi-yuan Hsu², Kristina Kordesch³ ${ }^{3}$ Erica Nicasio ${ }^{3}$, Alfredo Cortez ${ }^{4}$, lan McAlpine ${ }^{4}$, Sandra Brady ${ }^{3}$, Hanjing Zhuo ${ }^{3}$, Kirsten N Kangelaris ${ }^{5}$, John Stein ${ }^{4}$, Carolyn S Calfee ${ }^{6}$ and Kathleen D Liu ${ }^{2^{*}}$

\begin{abstract}
Background: Fibroblast growth factor-23 (FGF-23), a novel regulator of mineral metabolism, is markedly elevated in chronic kidney disease and has been associated with poor long-term outcomes. However, whether FGF-23 has an analogous role in acute kidney injury is unknown. The goal of this study was to measure FGF-23 levels in critically ill patients with acute kidney injury to determine whether FGF-23 levels were elevated, as in chronic kidney disease.
\end{abstract}

Methods: Plasma FGF-23 and intact parathyroid hormone (PTH) levels were measured in 12 patients with acute kidney injury and 8 control subjects.

Results: FGF-23 levels were significantly higher in acute kidney injury cases than in critically ill subjects without acute kidney injury, with a median FGF-23 level of $1948 \mathrm{RU} / \mathrm{mL}$ (interquartile range (IQR), 437-4369) in cases compared with $252 \mathrm{RU} / \mathrm{mL}(\mathrm{IQR}, 65-533)$ in controls $(p=0.01)$. No correlations were observed between FGF-23 and severity of acute kidney injury (defined by the Acute Kidney Injury Network criteria); among patients with acute kidney injury, FGF-23 levels were higher in nonsurvivors than survivors (median levels of 4446 RU/mL (IQR, 34555443) versus $544 \mathrm{RU} / \mathrm{mL}(\mathrm{IQR}, 390-1948 ; p=0.02)$. Severe hyperparathyroidism (defined as intact PTH >250 mg/dL) was present in 3 of 12 (25\%) of the acute kidney injury subjects versus none of the subjects without acute kidney injury, although this result did not meet statistical significance.

Conclusions: We provide novel data that demonstrate that FGF-23 levels are elevated in acute kidney injury, suggesting that FGF-23 dysregulation occurs in acute kidney injury as well as chronic kidney disease. Further studies are needed to define the short- and long-term clinical effects of dysregulated mineral metabolism in acute kidney injury patients.

\section{Introduction}

Acute kidney injury (AKI) is the most common reason for inpatient nephrology consultation and is associated with in-hospital mortality rates of $45-70 \%[1,2]$. Until recently, studies of AKI have focused on the epidemiology and management of AKI during the index hospitalization. However, AKI is now recognized as a disease with long-term sequelae, including increased risk of death and chronic kidney disease (CKD) progression [3-10]. The mechanisms by which AKI is linked to adverse long-term outcomes are poorly understood. Changes commonly found in CKD patients-anemia, acid/base dysregulation,

\footnotetext{
* Correspondence: Kathleen.Liu@ucsf.edu

Division of Nephrology, Department of Medicine, University of California, San Francisco, CA, USA

Full list of author information is available at the end of the article
}

altered mineral metabolism-likely occur in AKI patients, and as in CKD patients, may be responsible for some of these adverse long-term sequelae.

Dysregulated mineral metabolism, including derangements in calcium and phosphate levels, is relatively well characterized in CKD, and correction of hypocalcemia, vitamin D deficiency, and hyperphosphatemia in CKD patients is standard-of-care [11-13]. These derangements are all associated with an increased risk of death and cardiovascular outcomes in patients with CKD and end-stage renal disease [14-22]. Interestingly, although hypocalcemia and hyperphosphatemia are commonly observed in patients with AKI, the literature on dysregulated mineral metabolism in this patient population is relatively limited. Some papers have concentrated on rhabdomyolysis-induced AKI, where hyperphosphatemia

\section{SpringerOpen ${ }^{\circ}$}

(c) 2011 Zhang et al; licensee Springer. This is an Open Access article distributed under the terms of the Creative Commons Attribution License (http://creativecommons.org/licenses/by/2.0), which permits unrestricted use, distribution, and reproduction in any medium, provided the original work is properly cited. 
is extreme due to tissue breakdown [23-30]. Several studies included patients with AKI due to causes other than rhabdomyolysis [23,30-35], but these were published 30 or more years ago and did not measure more novel regulators of mineral metabolism, such as fibroblast growth factor-23 (FGF-23).

FGF-23 is a $26-\mathrm{kD}$ protein that is a novel, key regulator of phosphorus excretion and contributes to abnormal bone metabolism in CKD [36]. FGF-23 has been shown to be a strong, independent predictor of death in ESRD and CKD [37-39]. To date, only one case report has explored the impact of AKI on levels of FGF23 and that was in the setting of rhabdomyolysis [40]. We sought to determine the impact of AKI on FGF-23 and parathyroid hormone (PTH) levels in patients with AKI due to causes other than rhabdomyolysis. If FGF-23 is elevated in this context, we hypothesized that FGF-23 might represent a novel treatment target or a novel predictor for poor outcomes in patients with AKI.

\section{Methods}

\section{Study design, patient selection, and clinical data} collection

AKI cases and non-AKI control subjects (controls) were selected from two prospective observational cohort studies conducted at a tertiary care university hospital. Cases were identified from a prospective study of all patients with AKIN Stage I AKI [41] admitted to the adult intensive care unit of University of California San Francisco Medical Center between June 2006 and March 2009. Control subjects without AKI were identified from a prospective study of all critically ill Emergency Department patients eligible for admission to the adult intensive care unit of University of California San Francisco Medical Center from October 2008 to the present. The protocols were approved by the Institutional Committee on Human Research.

Baseline creatinine was defined as the lowest creatinine from the 365 days before admission until the episode of AKI for AKI subjects. For control subjects, baseline creatinine were the lowest creatinine from the 365 days before admission until hospital admission. Potential subjects with a baseline creatinine of greater than $1.1 \mathrm{mg} / \mathrm{dL}$ were excluded to eliminate subjects with underlying CKD, which would impact FGF-23 and PTH levels. Cause of AKI was determined by two nephrologists (KDL, RH) based on chart review. Each nephrologist independently reviewed the medical record to determine the cause of AKI; there was $100 \%$ agreement between the two reviewers.

\section{Biomarker measurements}

Plasma samples obtained from cases and controls were immediately spun at $3000 \mathrm{rpm}$ for 10 minutes and were aliquoted and stored at $-80^{\circ} \mathrm{C}$ until biomarker measurements were made. For AKI cases, samples were obtained at regular intervals during the first week that the patient met criteria for AKI; measurements were made on the sample from the time point closest to the peak serum creatinine. For controls, measurements were made on samples obtained immediately after admission. Intact PTH measurements were made using Immulite 2000 Intact PTH assay (Siemens, Deerfield IL). FGF-23 measurements were made using a C-terminal FGF-23 ELISA (Immutopics, San Clemente, CA) according to the manufacturer's instructions. The reported calcium and phosphorus measurements were made as part of routine clinical care; the reported measurements are the closest available relative to the time of biosample collection.

\section{Statistical analyses}

Baseline characteristics of cases and controls were first compared. Categorical variables were expressed as proportions, and compared using the $\chi^{2}$ test. Continuous variables were expressed as mean \pm standard deviation or median with interquartile range and were compared using the $t$ test or the Mann-Whitney rank-sum test, where appropriate. Spearman rank correlation coefficients were used to correlate FGF-23 levels with serum phosphorus, calcium, and PTH levels. Linear regression analysis was used to examine the relationship between FGF-23 levels and AKI status, after controlling for age and severity of illness, as measured by Acute Physiology And Chronic Health Evaluation (APACHE) II score [42]; because FGF-23 levels were not normally distributed, levels were natural log transformed for this analysis. Data analysis was conducted by using Stata 10.1 (StataCorp, College Station, TX). Two-tailed $p$ values $<0.05$ were considered significant.

\section{Results}

The baseline demographics and clinical characteristics of the 20 subjects in this study are summarized in Table 1. We studied 12 cases who developed at least Stage I AKI and 8 control subjects who did not. Cases and controls were similar with regard to sex and race. On average, cases were younger than controls $(57 \pm 12$ years versus $70 \pm 17$ years, $p=0.05$ ) and had lower APACHE II scores $(27 \pm 11$ versus $17 \pm 8, p=0.04)$. There was no statistically significant difference for in-hospital mortality rates between the two groups.

Subjects with AKI had a baseline serum creatinine of $67 \pm 15 \mu \mathrm{mol} / \mathrm{L}$ with a peak inpatient serum creatinine of $217 \pm 86 \mu \mathrm{mol} / \mathrm{L}$ compared with a baseline serum creatinine of $69 \pm 20 \mu \mathrm{mol} / \mathrm{L}$ and a peak serum creatinine of $81 \pm 17$ in non-AKI subjects ( $p<0.001$ for peak levels). As noted earlier, we excluded potential study subjects with a baseline creatinine greater than 97 
Table 1 Baseline characteristics of patients with and without acute kidney injury

\begin{tabular}{|c|c|c|c|}
\hline & No acute kidney injury & Acute kidney injury & $p$ value \\
\hline Number & 8 & 12 & \\
\hline Age $(y r)^{*}$ & $70 \pm 17$ & $57 \pm 12$ & 0.05 \\
\hline Male n (\%) & $2(25 \%)$ & $6(50 \%)$ & 0.37 \\
\hline Caucasian n (\%) & $4(50 \%)$ & $10(83 \%)$ & 0.16 \\
\hline APACHE $\|^{*}$ & $17 \pm 8$ & $27 \pm 11$ & 0.04 \\
\hline Death n (\%) & $3(38 \%)$ & $4(33 \%)$ & 1.00 \\
\hline Baseline $\mathrm{Cr}(\mu \mathrm{mol} / \mathrm{L})^{*}$ & $69 \pm 20$ & $67 \pm 15$ & 0.83 \\
\hline Peak $\mathrm{Cr}(\mathrm{mg} / \mathrm{dL})^{*}$ & $81 \pm 17$ & $217 \pm 86$ & $<0.001$ \\
\hline Dialysis n (\%) & $0(0 \%)$ & $4(33 \%)$ & 0.11 \\
\hline lonized calcium $(\mathrm{mmol} / \mathrm{L})^{*}$ & $1.15 \pm 0.08$ & $1.19 \pm 0.1$ & 0.41 \\
\hline Phosphorous (mmol/L)* & $3.3 \pm 1.1$ & $4.5 \pm 1$ & 0.02 \\
\hline
\end{tabular}

*Mean \pm SD

To convert $\mathrm{Cr}$ in $\mu \mathrm{mol} / \mathrm{L}$ to $\mathrm{mg} / \mathrm{dL}$, divide by 88.4

$\mu \mathrm{mol} / \mathrm{L}$ to avoid patients with underlying CKD. No patient had AKI attributable to rhabdomyolysis. Eight patients had acute tubular necrosis, two patients had AKI after orthotopic liver transplantation, one had cardiorenal syndrome, and one had multifactorial AKI. Two patients had Stage I AKI by the AKIN criteria [41], five patients had Stage II AKI, and five patients had Stage III AKI. Four of 12 (33\%) of the AKI subjects were treated with dialysis.

Subjects with and without AKI had mean ionized calcium levels of $1.19 \pm 0.1 \mathrm{mmol} / \mathrm{L}$ and $1.15 \pm 0.08$, respectively $(p=0.41)$. Serum phosphorus levels were significantly higher in AKI subjects compared with controls $(4.5 \pm 1 \mathrm{mmol} / \mathrm{L}$ versus $3.3 \pm 1.1 \mathrm{mmol} / \mathrm{L}$, $p=0.02$ ). The median intact PTH level was $63 \mathrm{mg} / \mathrm{dL}$ (25-75\% interquartile range (IQR), 38-213) in AKI subjects and $70 \mathrm{mg} / \mathrm{dL}$ (25-75\% IQR, 58-126) in controls (Figure $1 \mathrm{~A}, p=0.73)$. When severe hyperparathyroidism was defined as an intact PTH $>250 \mathrm{mg} / \mathrm{dL}$, a level that has been associated with increased cardiovascular disease risk in prior studies [43], none of the control subjects had a severe hyperparathyroidism but 3 of 12 (25\%) of the AKI subjects did (although this result did not meet conventional levels of statistical significance, $p=0.24$ ).

FGF-23 levels were significantly higher in critically ill AKI cases compared with critically ill non-AKI subjects, with a median FGF-23 level of 1948 RU/mL (IQR, 4374369 ) in AKI cases compared with $252 \mathrm{RU} / \mathrm{mL}$ (IQR, 65-533) in critically ill controls $(p=0.01$; Figure $1 \mathrm{~B})$. After adjusting for age and APACHE II as potential confounders, AKI remained a significant predictor of log-transformed FGF-23 levels (Table 2). Among patients with AKI, FGF-23 levels were higher in nonsurvivors $(n=4)$ compared with survivors $(n=8)$, with respective median levels of $4446 \mathrm{RU} / \mathrm{mL}$ (IQR, 34555443 ) versus $544 \mathrm{RU} / \mathrm{mL}$ (IQR, 390-1948; $p=0.02$ ). Although serum phosphorus and FGF-23 levels were both elevated in AKI subjects, no correlation was observed between the two variables, as shown in Figure 2 $(\mathrm{r}=0.08, p=0.74)$. There was a correlation between PTH and FGF-23 levels $(r=0.55, p=0.02)$; when this analysis was restricted to patients with AKI, this correlation only had borderline statistical significance $(r=0.58$, $p=0.05)$, likely due to the small size of the cohort.

\section{Discussion}

In this cross-sectional case series, we report for the first time that critically ill patients with AKI due to causes other than rhabdomyolysis have elevated FGF-23 levels compared with critically ill controls. Among patients with AKI, elevated FGF-23 levels were associated with an increased risk of death. As expected, AKI patients had, on average, higher concentrations of serum phosphorous compared with patients without AKI. In addition, a larger proportion of AKI patients had significant hyperparathyroidism compared with controls, although this result did not meet statistical significance. These results suggest that dysregulated mineral metabolism is common in AKI, analogous to CKD.

Interestingly, no correlation was observed between phosphorous and FGF-23 levels in this study. Few reports have analyzed this relationship in AKI patients, although in ESRD a patient's degree of elevation in FGF-23 is often correlated with severity of hyperphosphatemia $[38,44,45]$. In CKD, elevated FGF-23 levels are thought to be due to increased secretion by bone cells, rather than due to decreased renal clearance $[46,47]$. Comparison of levels of intact versus degraded FGF-23 in patients on maintenance hemodialysis suggest that there is no increase in FGF-23 degradation products in these subjects and that decreased clearance of FGF-23 is therefore not the mechanism for increased FGF-23 levels [48]. Therefore, as in CKD, elevated FGF-23 levels in AKI are likely not due to decreased clearance of FGF-23 and highlight the 

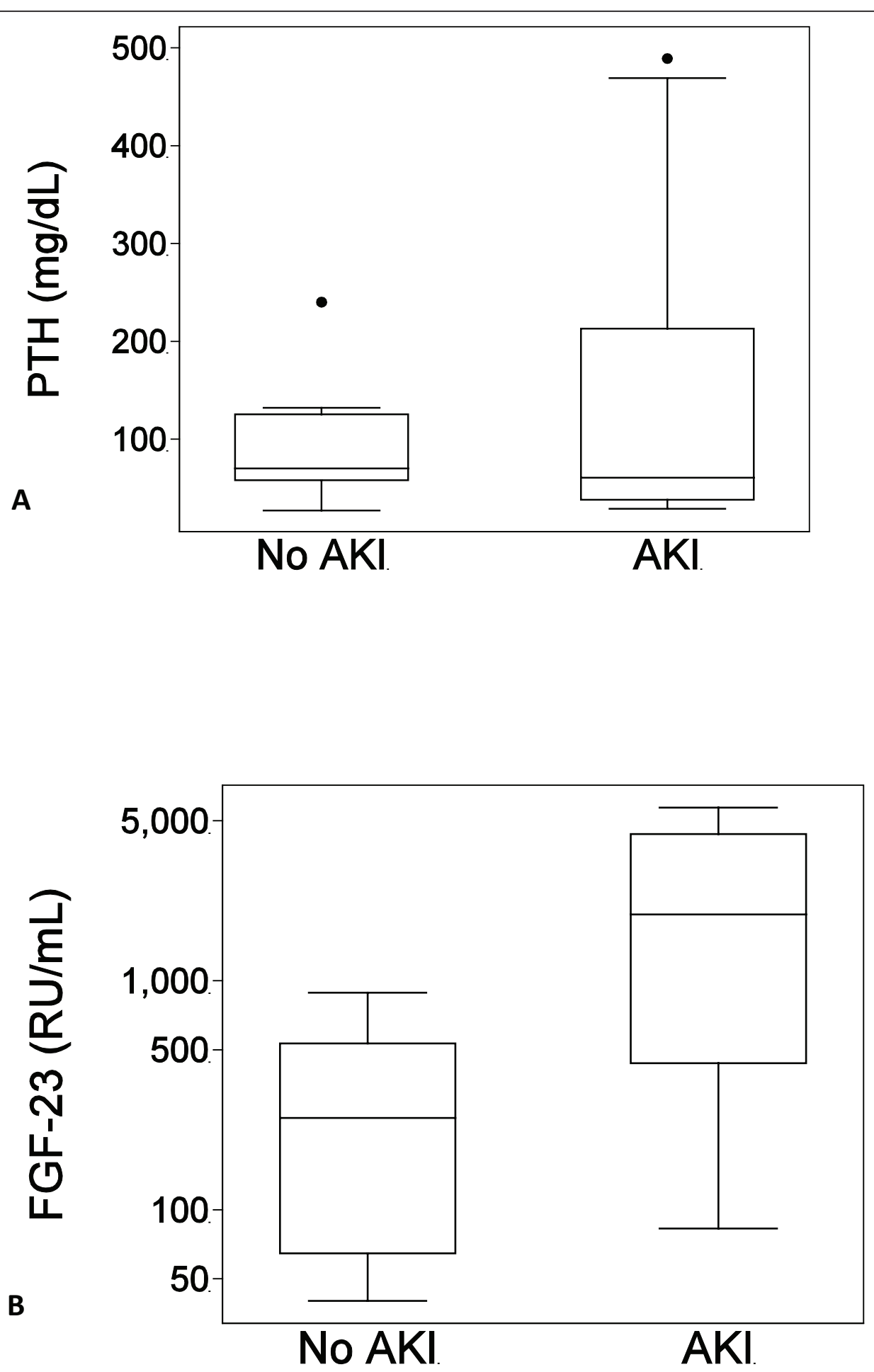

Figure 1 PTH and FGF-23 levels in non-AKI and AKI subjects. A There was no overall difference in PTH levels between AKI and non-AKI subjects $(p=0.73)$. B FGF-23 levels were significant higher in patients with AKI compared with non-AKI subjects $(p=0.01)$. 
Table 2 Association of log-transformed FGF-23 levels with AKI (multivariable linear regression)

\begin{tabular}{lccc}
\hline Predictor & Coefficient & $\mathbf{9 5 \%} \mathbf{C l}$ & $\boldsymbol{p}$ value \\
\hline AKI & 1.81 & $0.37-3.25$ & 0.02 \\
Age* $^{*}$ & 0.29 & $-0.15-0.73$ & 0.18 \\
APACHE II score & 0.05 & $-0.02-0.11$ & 0.14 \\
\hline
\end{tabular}

*Per 10-year increase

important paracrine role of the kidney, even in an acute illness (e.g., AKI).

Elevation of FGF-23 during AKI may have several implications. In ESRD patients undergoing hemodialysis, high FGF-23 concentrations are associated with early mortality, with an increased risk as high as $600 \%$ $[37,38]$. Our study demonstrated an association between FGF-23 levels and death in subjects with AKI, although relatively small. If the association between elevated FGF23 levels and death is confirmed in a larger study of patients with AKI, prevention or treatment of such processes could become a priority in AKI management. Treatment with phosphate binders and calcimimetics (Cinacalcet) has been shown to lower FGF-23 levels [49-51]. Treatments that are tailored more toward AKIinduced mineral dysregulation could be developed as further information is gathered about the exact role of
FGF-23 in AKI. At present, there are no evidence-based guidelines about target goals for maintaining serum phosphorus levels. Treatments that improve the longterm outcomes of patients with AKI are needed, and dysregulated mineral metabolism, including FGF-23 levels, may represent a therapeutic target in AKI that is highly amenable to intervention.

There are several limitations in this study, including small sample size and relatively short follow-up time. Because FGF-23 levels were not measured repeatedly, duration of FGF-23 elevation also was unclear. Nevertheless, this is the first study to report an association between FGF-23 and non-rhabdomyolysis-related AKI, and that among patients with AKI, higher FGF-23 levels are associated with an increased risk of death. Larger and long-term studies should be conducted to clarify the impact of FGF-23 elevation among AKI patients.

\section{Conclusions}

Dysregulated mineral metabolism is a poorly understood aspect of acute kidney injury. We demonstrated for the first time that FGF-23, a critical regulator of mineral metabolism in chronic kidney disease, is upregulated during acute kidney injury from causes other than

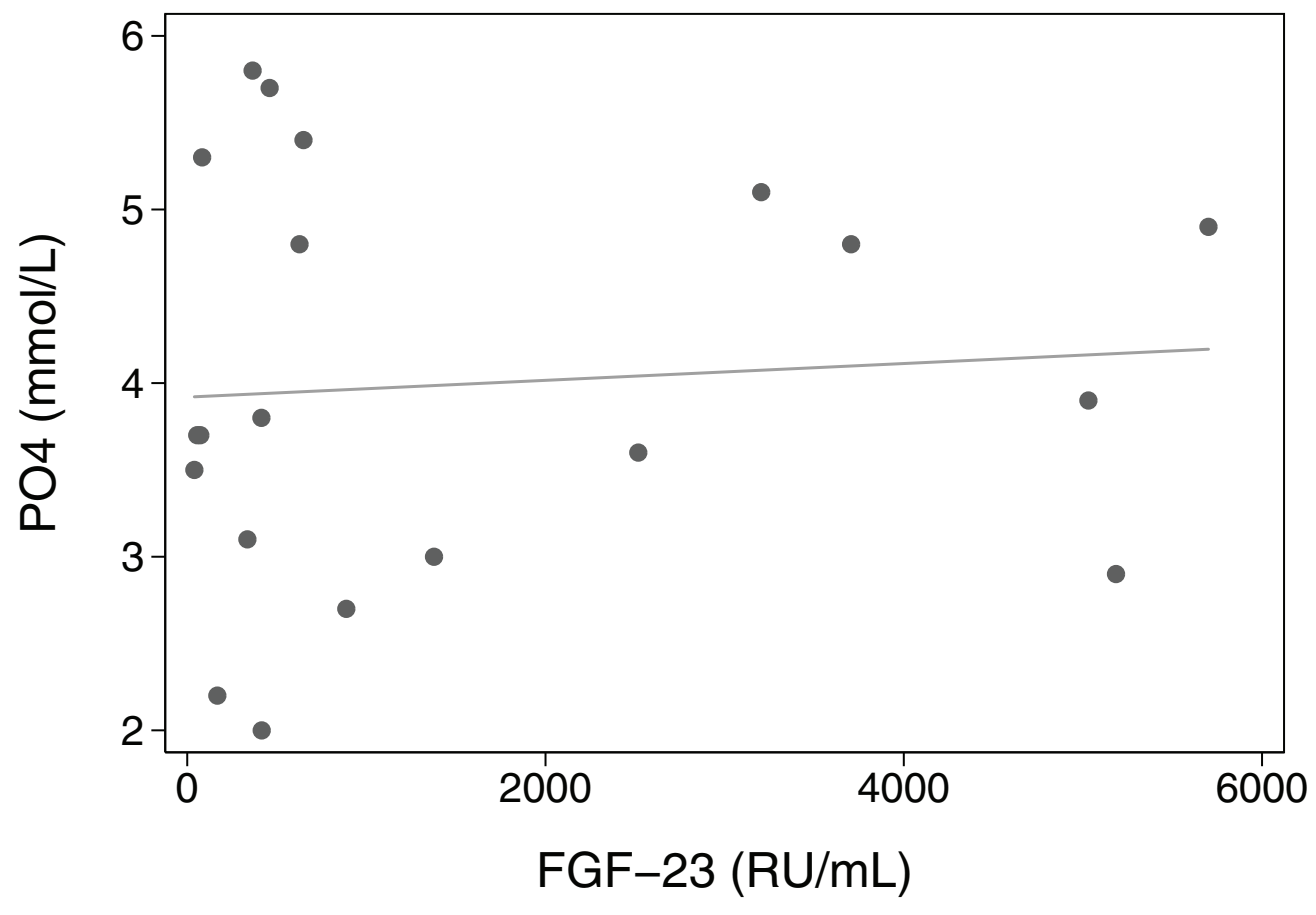

Figure 2 Correlation of serum phosphorus (PO4) and FGF-23 levels in patients with and without acute kidney injury. No correlation was observed between PO4 and FGF-23 levels ( $r=0.08, p=0.74$ ). 
rhabdomyolysis. Furthermore, high FGF-23 levels are associated with mortality in patients with AKI.

\section{Acknowledgements}

This study was supported by the following funding sources: Albert Einstein College of Medicine (MZ); HL090833 (CSC); Flight Attendant Medical Research Institute (CSC); UCSF Department of Medicine (CSC and KDL); KL2 RR024130 (KDL).

\section{Author details \\ ${ }^{1}$ Albert Einstein College of Medicine, Yeshiva University, New York, NY, USA ${ }^{2}$ Division of Nephrology, Department of Medicine, University of California, San Francisco, CA, USA ${ }^{3}$ Cardiovascular Research Institute, University of California, San Francisco, USA ${ }^{4}$ Department of Emergency Medicine, University of California, San Francisco, CA, USA ${ }^{5}$ Division of Hospital Medicine, Department of Medicine, University of California, San Francisco, CA, USA ${ }^{6}$ Division of Pulmonary and Critical Care Medicine, Department of Medicine, University of California, San Francisco, CA, USA}

\section{Authors' contributions}

$\mathrm{MZ}$ and RH were responsible for data analysis and manuscript preparation. $\mathrm{CYH}$ was responsible for study design, data analysis, and manuscript preparation. KK, EN, AC, and IA were responsible for the execution of the study, including screening and consenting eligible study subjects, data collection, data analysis, and manuscript preparation. $\mathrm{HZ}$ was responsible for database management and data analysis. SB was responsible for FGF-23 measurements. KNK, JS, and CSC were responsible for design of the study and manuscript preparation. KDL was responsible for study design, biomarker measurements, data analysis, and manuscript preparation.

\section{Competing interests}

The authors declare that they have no competing interests.

Received: 8 March 2011 Accepted: 14 June 2011

Published: 14 June 2011

\section{References}

1. Uchino S, Kellum JA, Bellomo R, Doig GS, Morimatsu H, Morgera S, Schetz M, Tan I, Bouman C, Macedo E, Gibney N, Tolwani A, Ronco C: Acute renal failure in critically ill patients: a multinational, multicenter study. JAMA 2005, 294:813-818.

2. Mehta R, Pascual M, Soroko S, Savage B, Himmelfarb J, Ikizler T, Paganini E, Chertow G: Spectrum of acute renal failure in the intensive care unit: the PICARD experience. Kidney Int 2004, 66:1613-1621.

3. Morgera S, Schneider M, Neumayer HH: Long-term outcomes after acute kidney injury. Crit Care Med 2008, 36:S193-S197.

4. Newsome BB, Warnock DG, McClellan WM, Herzog CA, Kiefe Cl, Eggers PW, Allison JJ: Long-term risk of mortality and end-stage renal disease among the elderly after small increases in serum creatinine level during hospitalization for acute myocardial infarction. Arch Intern Med 2008, 168:609-616.

5. Ishani A, Xue JL, Himmelfarb J, Eggers PW, Kimmel PL, Molitoris BA, Collins AJ: Acute kidney injury increases risk of ESRD among elderly. J Am Soc Nephrol 2009, 20:223-228.

6. Lo L, Go AS, Chertow GM, McCulloch CE, Fan D, Ordonez JD, Hsu CY: Dialysis-requiring acute renal failure increases the risk of progressive chronic kidney disease. Kidney Int 2009, 76:893-899.

7. Hsu CY, Chertow GM, McCulloch CE, Fan D, Ordonez JD, Go AS: Nonrecovery of kidney function and death after acute on chronic renal failure. Clin J Am Soc Nephrol 2009, 4:891-898.

8. Amdur RL, Chawla LS, Amodeo S, Kimmel PL, Palant CE: Outcomes following diagnosis of acute renal failure in U.S. veterans: focus on acute tubular necrosis. Kidney Int 2009, 76:1089-1097.

9. Wald R, Quinn RR, Luo J, Li P, Scales DC, Mamdani MM, Ray JG: Chronic dialysis and death among survivors of acute kidney injury requiring dialysis. JAMA 2009, 302:1179-1185.

10. Lafrance JP, Miller DR: Acute kidney injury associates with increased longterm mortality. J Am Soc Nephrol 2010, 21:345-352.
11. K/DOQI clinical practice guidelines for bone metabolism and disease in chronic kidney disease. Am J Kidney Dis 2003, 42:S1-S201.

12. KDIGO clinical practice guideline for the diagnosis, evaluation, prevention, and treatment of Chronic Kidney Disease-Mineral and Bone Disorder (CKD-MBD). Kidney Int Suppl 2009, S1-130.

13. Uhlig K, Berns JS, Kestenbaum B, Kumar R, Leonard MB, Martin K, Sprague SM, Goldfarb S: KDOQI US commentary on the 2009 KDIGO Clinical Practice Guideline for the Diagnosis, Evaluation, and Treatment of CKD-Mineral and Bone Disorder (CKD-MBD). Am J Kidney Dis 2010, 55:773-799.

14. Ganesh SK, Stack AG, Levin NW, Hulbert-Shearon T, Port FK: Association of elevated serum $\mathrm{PO} 4, \mathrm{Ca} \times \mathrm{PO} 4$ product, and parathyroid hormone with cardiac mortality risk in chronic hemodialysis patients. Journal of the American Society of Nephrology 2001, 12:2131-2138.

15. Block GA, Klassen PS, Lazarus JM, Ofsthun N, Lowrie EG, Chertow GM: Mineral metabolism, mortality, and morbidity in maintenance hemodialysis. J Am Soc Nephrol 2004, 15:2208-2218.

16. Kalantar-Zadeh K, Kuwae N, Regidor DL, Kovesdy CP, Kilpatrick RD, Shinaberger CS, MCAllister CJ, Budoff MJ, Salusky IB, Kopple JD: Survival predictability of time-varying indicators of bone disease in maintenance hemodialysis patients. Kidney Int 2006, 70:771-780.

17. Young EW, Albert JM, Satayathum S, Goodkin DA, Pisoni RL, Akiba T, Akizawa T, Kurokawa K, Bommer J, Piera L, Port FK: Predictors and consequences of altered mineral metabolism: the Dialysis Outcomes and Practice Patterns Study. Kidney Int 2005, 67:1179-1187.

18. Kestenbaum B, Sampson JN, Rudser KD, Patterson DJ, Seliger SL, Young B, Sherrard DJ, Andress DL: Serum phosphate levels and mortality risk among people with chronic kidney disease. J Am Soc Nephrol 2005, 16:520-528.

19. Wolf M, Shah A, Gutierrez O, Ankers E, Monroy M, Tamez H, Steele D, Chang Y, Camargo CA Jr, Tonelli M, Thadhani R: Vitamin D levels and early mortality among incident hemodialysis patients. Kidney Int 2007, 72:1004-1013.

20. Wang AY, Lam CW, Sanderson JE, Wang M, Chan IH, Lui SF, Sea MM, Woo J: Serum 25-hydroxyvitamin D status and cardiovascular outcomes in chronic peritoneal dialysis patients: a 3-y prospective cohort study. Am J Clin Nutr 2008, 87:1631-1638.

21. Ravani P, Malberti F, Tripepi G, Pecchini P, Cutrupi S, Pizzini P, Mallamaci F, Zoccali C: Vitamin D levels and patient outcome in chronic kidney disease. Kidney Int 2009, 75:88-95.

22. Mehrotra R, Kermah DA, Salusky IB, Wolf MS, Thadhani RI, Chiu YW, Martins D, Adler SG, Norris KC: Chronic kidney disease, hypovitaminosis D, and mortality in the United States. Kidney Int 2009, 76:977-983.

23. Shrestha SM, Berry JL, Davies M, Ballardie FW: Biphasic hypercalcemia in severe rhabdomyolysis: serial analysis of PTH and vitamin D metabolites. A case report and literature review. Am J Kidney Dis 2004, 43:e31-e35.

24. Shieh $S D$, Lin YF, Lin SH, Lu KC: A prospective study of calcium metabolism in exertional heat stroke with rhabdomyolysis and acute renal failure. Nephron 1995, 71:428-432.

25. Llach F, Felsenfeld AJ, Haussler MR: The pathophysiology of altered calcium metabolism in rhabdomyolysis-induced acute renal failure. Interactions of parathyroid hormone, 25-hydroxycholecalciferol, and 1,25-dihydroxycholecalciferol. N Engl J Med 1981, 305:117-123.

26. Sperling LS, Tumlin JA: Case report: delayed hypercalcemia after rhabdomyolysis-induced acute renal failure. Am J Med Sci 1996, 311:186-188.

27. Motellon JL, Bernis C, Gruss E, Traver JA: Role of parathyroid hormone and 1,25 dihydroxycholecalciferol in calcium homeostasis of rhabdomyolysis. Nephrol Dial Transplant 1995, 10:299-300.

28. Akmal M, Bishop JE, Telfer N, Norman AW, Massry SG: Hypocalcemia and hypercalcemia in patients with rhabdomyolysis with and without acute renal failure. J Clin Endocrinol Metab 1986, 63:137-142.

29. Prince RL, Hutchison BG, Bhagat Cl: Hypercalcemia during resolution of acute renal failure associated with rhabdomyolysis: evidence for suppression of parathyroid hormone and calcitriol. Aust N Z J Med 1986, 16:506-508.

30. Pietrek J, Kokot F, Kuska J: Kinetics of serum 25-hydroxyvitamin D in patients with acute renal failure. Am J Clin Nutr 1978, 31:1919-1926.

31. Mallette $L E$, Silverman V: Hypercalcemia after acute renal failure. South Med J 1980, 73:1453-1456. 
32. Weinstein RS, Hudson JB: Parathyroid hormone and 25hydroxycholecalciferol levels in hypercalcemia of acute renal failure. Arch Intern Med 1980, 140:410-411.

33. Chertow BS, Plymate SR, Becker FO: Vitamin-D-resistant idiopathic hypoparathyroidism. Acute hypercalcemia during acute renal failure. Arch Intern Med 1974, 133:838-840.

34. Massry S, Arieff A, Coburn J, Palmieri G, Kleeman C: Divalent ion metabolism in patients with acute renal failure: studies on the mechanism of hypocalcemia. Kidney Int 1974, 5:437-445

35. Madsen S, Olgaard K, Ladefoged J: Suppressive effect of 1,25dihydroxyvitamin D3 on circulating parathyroid hormone in acute renal failure. J Clin Endocrinol Metab 1981, 53:823-827.

36. Wolf M: Forging Forward with 10 burning questions on FGF23 in kidney disease. J Am Soc Nephrol 2010, 21:1427-1435.

37. Gutierrez OM, Mannstadt M, Isakova T, Rauh-Hain JA, Tamez H, Shah A, Smith K, Lee H, Thadhani R, Juppner H, Wolf M: Fibroblast growth factor 23 and mortality among patients undergoing hemodialysis. N Engl J Med 2008, 359:584-592.

38. Jean G, Terrat JC, Vanel T, Hurot JM, Lorriaux C, Mayor B, Chazot C: High levels of serum fibroblast growth factor (FGF)-23 are associated with increased mortality in long haemodialysis patients. Nephrol Dial Transplant 2009, 24:2792-2796.

39. Hsu CY: FGF-23 and outcomes research-when physiology meets epidemiology. N Engl J Med 2008, 359:640-642.

40. Leaf DE, Wolf M, Stern L: Elevated FGF-23 in a patient with rhabdomyolysis-induced acute kidney injury. Nephrol Dial Transplant 2010, 25:1335-1337.

41. Mehta RL, Kellum JA, Shah SV, Molitoris BA, Ronco C, Warnock DG, Levin A: Acute Kidney Injury Network: report of an initiative to improve outcomes in acute kidney injury. Crit Care 2007, 11:R31.

42. Knaus WA, Draper EA, Wagner DP, Zimmerman JE: APACHE II: a severity of disease classification system. Crit Care Med 1985, 13:818-829.

43. Soubassi LP, Chiras TC, Papadakis ED, Poulos GD, Chaniotis DI, Tsapakidis IP, Soubassi SP, Zerefos SN, Zerefos NS, Valis DA: Incidence and risk factors of coronary heart disease in elderly patients on chronic hemodialysis. Int Urol Nephrol 2006, 38:795-800.

44. Imanishi Y, Inaba M, Nakatsuka K, Nagasue K, Okuno S, Yoshihara A, Miura M, Miyauchi A, Kobayashi K, Miki T, Shoji T, Ishimura E, Nishizawa Y: FGF-23 in patients with end-stage renal disease on hemodialysis. Kidney Int 2004, 65:1943-1946.

45. Sato T, Tominaga Y, Ueki T, Goto N, Matsuoka S, Katayama A, Haba T, Uchida K, Nakanishi S, Kazama JJ, Gejyo F, Yamashita T, Fukagawa M: Total parathyroidectomy reduces elevated circulating fibroblast growth factor 23 in advanced secondary hyperparathyroidism. Am J Kidney Dis 2004, 44:481-487.

46. Seiler S, Heine GH, Fliser D: Clinical relevance of FGF-23 in chronic kidney disease. Kidney Int Suppl 2009, S34-S42.

47. Wolf M: Forging forward with 10 burning questions on FGF23 in kidney disease. J Am Soc Nephrol JASN 2010, 21:1427-1435.

48. Imanishi Y, Inaba M, Nakatsuka K, Nagasue K, Okuno S, Yoshihara A, Miura M, Miyauchi A, Kobayashi K, Miki T, Shoji T, Ishimura E, Nishizawa Y: FGF-23 in patients with end-stage renal disease on hemodialysis. Kidney international 2004, 65:1943-1946.

49. Oliveira RB, Cancela AL, Graciolli FG, Dos Reis LM, Draibe SA, Cuppari L, Carvalho AB, Jorgetti V, Canziani ME, Moyses RM: Early control of PTH and FGF23 in normophosphatemic CKD patients: a new target in CKD-MBD therapy? Clin J Am Soc Nephrol 2010, 5:286-291.

50. Wetmore JB, Liu S, Krebill R, Menard R, Quarles LD: Effects of cinacalcet and concurrent low-dose vitamin D on FGF23 levels in ESRD. Clin J Am Soc Nephrol 2010, 5:110-116.

51. Zisman AL, Wolf M: Recent advances in the rapidly evolving field of fibroblast growth factor 23 in chronic kidney disease. Curr Opin Nephrol Hypertens 2010, 19:335-342.

doi:10.1186/2110-5820-1-21

Cite this article as: Zhang et al.: FGF-23 and PTH levels in patients with acute kidney injury: A cross-sectional case series study. Annals of Intensive Care 2011 1:21.

\section{Submit your manuscript to a SpringerOpen ${ }^{\circ}$ journal and benefit from:}

- Convenient online submission

- Rigorous peer review

- Immediate publication on acceptance

- Open access: articles freely available online

- High visibility within the field

- Retaining the copyright to your article

Submit your next manuscript at $\gg$ springeropen.com 